\title{
Epibenthic colonization of concrete and steel pilings in a cold-temperate embayment: a field experiment
}

\author{
Mathias H. Andersson • Matz Berggren • \\ Dan Wilhelmsson · Marcus C. Öhman
}

Received: 18 April 2008 / Revised: 20 February 2009 / Accepted: 27 February 2009 / Published online: 22 March 2009

(C) Springer-Verlag and AWI 2009

\begin{abstract}
With large-scale development of offshore wind farms, vertical structures are becoming more common in open water areas. To examine how vertical structures of different materials may be colonized by epibenthic organisms, an experiment was carried out using steel and concrete pilings constructed to resemble those commonly used in wind farm constructions as well as in bridges, jetties and oil platforms. The early recruitment and succession of the epibenthic communities were sampled once a month for the first 5 months and then again after 1 year. Further, the fish assemblages associated with the pillars were sampled and compared to natural areas. The main epibenthic species groups, in terms of coverage, differed between the two materials at five out of six sampling occasions. Dominant organisms on steel pillars were the barnacle Balanus improvisus, the calcareous tubeworm Pomatoceros triqueter and the tunicate Ciona intestinalis. On the concrete pillars, the hydroid Laomedea sp. and the tunicates Corella parallelogramma and Ascidiella spp. dominated. However, there was no different in coverage at different heights on the pillars or in biomass and species abundance at different directions
\end{abstract}

Communicated by H.-D. Franke.

Electronic supplementary material The online version of this article (doi:10.1007/s10152-009-0156-9) contains supplementary material, which is available to authorized users.

M. H. Andersson $(\bowtie) \cdot$ D. Wilhelmsson · M. C. Öhman

Department of Zoology, Stockholm University,

10691 Stockholm, Sweden

e-mail: mathias.andersson@ zoologi.su.se

\section{Berggren}

Department of Marine Ecology, Göteborg University, Kristineberg Marine Research Station,

45034 Fiskebäckskil, Sweden (north-east or south-west) 5 months after submergence. Fish showed overall higher abundances and species numbers on the pillars (but no difference between steel and concrete) compared to the surrounding soft bottom habitats but not compared to natural vertical rock walls. Two species were attracted to the pillars, indicating a reef effect; Gobiusculus flavescens and Ctenolabrus rupestris. The bottom-dwelling gobies, Pomatoschistus spp., did not show such preferences.

Keywords Artificial reef - Disturbance - Habitat structure Reef effect $\cdot$ Renewable energy $\cdot$ Tunicates

\section{Introduction}

Man-made submerged structures are present in most urbanized coastal areas. By adding such structures to the aquatic environment, habitat composition is altered and as a result, the local flora and fauna may change. Marine life has been noticed to be influenced by the presence of bridges, shipwrecks, oil rigs, piers, pontoons and wind turbine foundations (Bacchiocchi and Airoldi 2003; Perkol-Finkel et al. 2006; Petersen and Malm 2006; Wilhelmsson et al. 1998, 2006a). In addition, submerged materials including artificial reefs and fish aggregations devices are applied worldwide to locally increase production and aggregate aquatic life or to restore damaged reefs (Rilov and Benayahu 1998; Nelson 2003; Girard et al. 2004; Reed et al. 2006).

Although submerged structures have a long history of being used for resource enhancement in various areas, their applicability and function are still debated (Bohnsack 1989; Polovina 1989; Pickering and Whitmarsh 1997; Jensen et al. 2000; Svane and Petersen 2001; Sayer et al. 2005). Further, research on the ecological effects of submerged structures has mainly been carried out in tropical or temperate 
waters (reviewed in Jensen et al. 2000; Baine 2001). Coldtemperate environments, as found in northern Europe, have received less attention (but see Malm 2005; Qvarfordt et al. 2006; Wilhelmsson et al. 2006a, b; Zettler and Pollehne 2006; Andersson et al. 2007) even though man-made structures are commonly found in those waters. Notably, there are limits to how far knowledge achieved from warmer waters can be extrapolated to higher latitudes given their differences in seasonal fluctuations in terms of water temperature and light availability.

Substrate composition and surface heterogeneity of the introduced structures are important factors for settling organisms (Mullineaux and Garland 1993; Walters and Wethey 1996; Becerra-Muñoz and Schramm Jr 2007). Settling larvae of various species have different preferences for flow speeds of the boundary layer and chemical cues from resident species may also play a role (Mullineaux and Butman 1991; Koehl 2007). Larvae can actively discard a non-suitable surface as noticed in studies involving especially barnacles (Lemire and Bourget 1996; Berntsson et al. 2000). Since larval supply is linked to season, time of submergence could determine what the first colonizer will be (Anderson and Underwood 1994; Qvarfordt et al. 2006). In the succession that may follow the interactions between resident species and new colonizers could further influence patterns of colonization (Connell and Slatyer 1977). Two of the most commonly used materials in underwater constructions, steel and concrete (Baine 2001), have rarely been compared in terms of the ecological effects of their presence in marine waters (but see Anderson and Underwood 1994; Brown 2005). For a settling organism, these two types of substrates offer different micro-scale environments with different surface heterogeneity and material composition and as a consequence, different communities would be expected to develop (Foster 1975; Wahl 1989; Guilbeau et al. 2003; Svane and Petersen 2001).

In addition to sessile organisms that proliferate attached to the surface, mobile organisms may also associate with underwater structures. Fish are commonly found in high numbers in close association with brig pillars, oil-rig and wind turbine foundations, and other artificial structures, and may utilize the sessile assemblage for food and shelter (Wilhelmsson et al. 2006a; Clynick et al. 2007; Moreau et al. 2008).

Vertical cylindrical artificial structures are found in all seas and will increase in the future; not least due to the fact that thousands of offshore wind turbines are planned to be built in northern Europe alone, within the next decade (IEA 2008). Concerns about the ecological impact of these offshore wind farms to the marine community have been debated (Gill and Kimber 2005; Petersen and Malm 2006; Zettler and Pollehne 2006). Knowledge is needed about their ecological effect in order for environmental managers to make ecologically correct decisions about managing urbanized coastal areas. In addition, large infrastructural structures should not be regarded as surrogates for natural substrates since the epibenthic assemblages on these surfaces are shown to differ compared to assemblages on natural hard substrates (Connell 2001; Badalamenti et al. 2002; Bulleri et al. 2005; Perkol-Finkel et al. 2006). However, there are few experimental that use standardized units of different materials to evaluate the effect of different substrates on the development of the epibenthic assemblage (but see Chapman and Clynick 2006). The current regime around a cylindrical structure is different from commonly used panels or complexed constructed artificial reefs in colonization studies and will influence the epibenthic development (Mullineaux and Garland 1993; Lemire and Bourget 1996; Guichard et al. 2001). In addition, diversity in marine invertebrate assemblages has been shown to be scaledependent (Keough 1984; Sousa 1984; Eggleston et al. 1999).

The aim of the present study was to follow the early recruitment and succession of epibenthic invertebrates and algae on constructed vertical cylindrical structures that resemble commonly applied man-made foundations such as offshore wind turbines, bridge pillars and jetties. Twelve experimental pillars of the same size and shape were constructed in steel or concrete, and submerged on the same day. The fish community was also studied as fish may associate with submerged structures and could be linked to the epibenthos on the pillars. We predicted that the epibenthic assemblages on the two materials would be different in terms of species coverage and diversity as a consequence of the dissimilarity in surface heterogeneity and material composition. Furthermore, we expected the distribution patterns of local fish assemblages to be influenced by the introduction of the artificial structures. Natural soft bottoms and vertical rock walls were used as references for common species in the area.

\section{Materials and methods}

Study area

This study was carried out from May 2005 to May 2006 in Gåsevik bay near Kristineberg Marine Research Station on the west coast of Sweden (Fig. 1). The bay is located in a north-south direction and it is semi-enclosed by a small archipelago. It covers an area of approximately $300 \mathrm{~m} \times$ $300 \mathrm{~m}$ with a bottom substrate of sand, mud and shell gravel. The bottom follows a gentle slope from a depth of 3-10 m. Two sandbanks at a depth of $3 \mathrm{~m}$, opposite the landward side, create a small strait where the slope is located.

During the survey period, the temperature of the surface water $(0-10 \mathrm{~m})$ fluctuated from 0 to $21^{\circ} \mathrm{C}$, and the salinity 


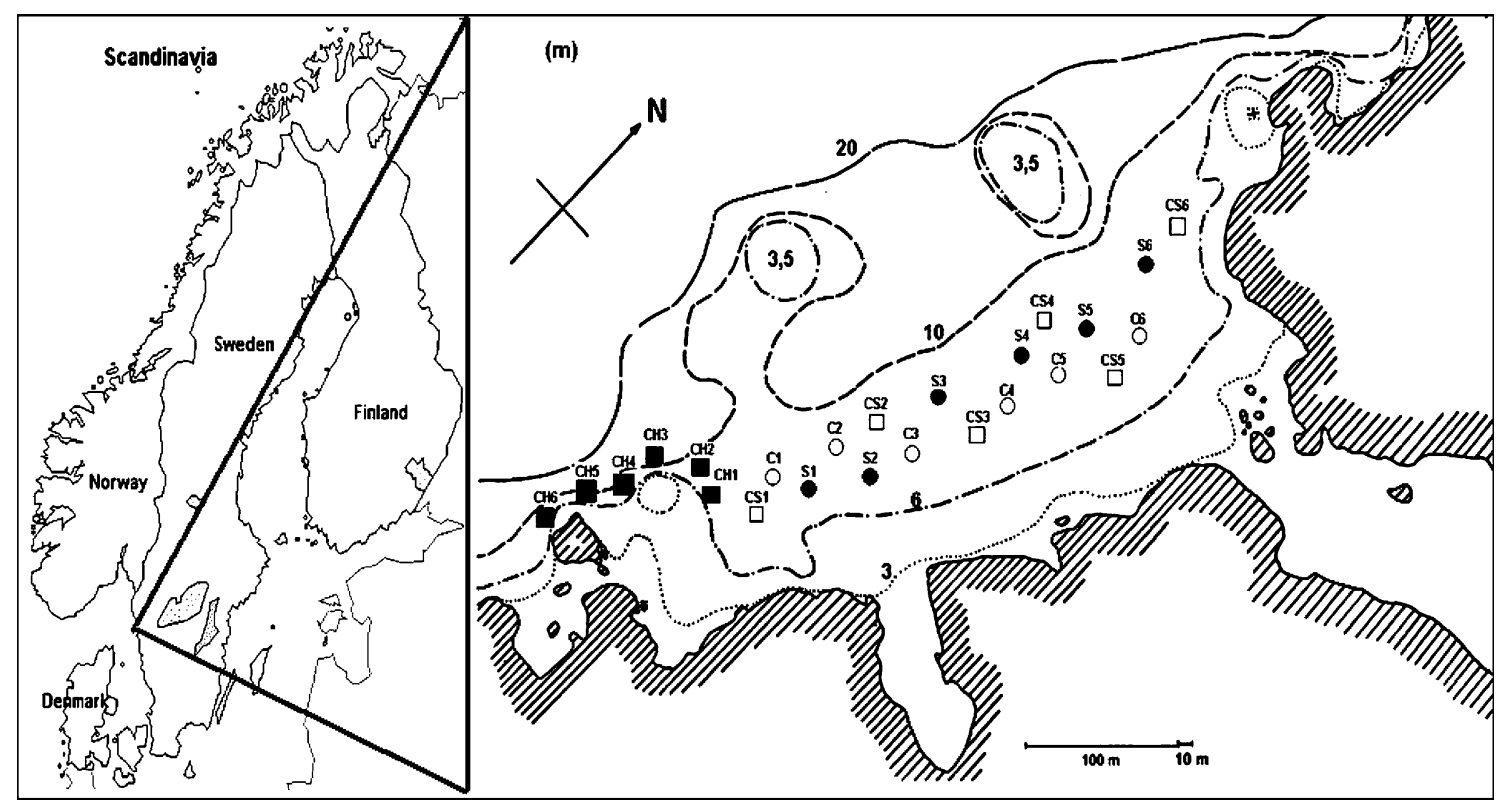

Fig. 1 Map over Scandinavia with the study site Gåsevik bay and location of pillars within the bay and reference sites out marked: open circle concrete pillars $(C)$, dark filled circle steel pillars $(S)$, open square control soft bottom $(C S)$, dark filled square control rock walls $(\mathrm{CH})$

between 13 and 32 ppt. Wind speeds varied from 2 to $15 \mathrm{~ms}^{-1}$ and the wave height had a mean of $0.5 \mathrm{~m}$ (SMHI 2006). The principal current direction varied between north-east and south-west in the bay. Tidal fluctuations along the Swedish west coast are within $0.3 \mathrm{~m}$. Secchi depths were recorded at 6-8 $\mathrm{m}$ throughout the study period. Ice covered some parts of adjacent waters during the winter months (i.e. December-March).

\section{Pillar design}

For the experiment, six steel pillars (Cor-ten steel which has high rust resistance) and six concrete pillars were constructed; each cylindrical pillar measuring $1.5 \mathrm{~m}$ in height and $0.4 \mathrm{~m}$ in diameter and weighting about $250 \mathrm{~kg}$ (Fig. 2). The pillars were deployed in a row in 6-8 $\mathrm{m}$ depth (buried about $35 \mathrm{~cm}$ into the sediment for stabilization). The row alternated between concrete and steel pillars that were set at least $20 \mathrm{~m}$ apart (Fig. 1). Twelve sites on natural bottoms (six on the soft bottom habitat and six on vertical rock walls) were randomly chosen for a description of the natural faunal communities in the area (Fig. 1).

Method

The study aimed to follow the early recruitment and succession of the epibenthic organisms and fish on the vertical surfaces of the pillars over a period of 5 months with sampling once a month, using photographing and scrape-off samples. The pillars were submerged on 2 May 2005 and sampled once a month $(29,64,94,129$ and 154 days after submergence, respectively). An opportunity arose to return to the bay in the beginning of May 2006 (366 days after submergence) and perform a limited survey. It did not include scrape-off samples due to time limitations, but pictures were taken and fish numbers were counted. All sampling was conducted between 10.00 and 16.00 by scuba divers.

Two digital photos were taken of the epibenthic assemblages on each pillar at all sampling occasions, of areas that had been marked in advance at random directions within a rectangle measuring $14 \mathrm{~cm} \times 10 \mathrm{~cm}\left(140 \mathrm{~cm}^{2}\right)$. The areas were located 30 and $60 \mathrm{~cm}$ from the seabed to minimize the edge effect (Fig. 2). Coverage of individual species and species groups were calculated using UTHSCSA ImageTool version 3.0. Second, in order to achieve more detailed information about organisms in the pictures, some scrapeoff samples were taken at sampling occasions $1-4$. At sampling occasion 5 (154 days after submergence), all pillars were sampled on the sides facing north-east and south-west, $60 \mathrm{~cm}$ above the seafloor, in order to compare the different sides of the pillars as well as the two materials in terms of biomass and species abundance. All biota in a square of $10 \mathrm{~cm} \times 10 \mathrm{~cm}$ was collected using a scraper and $1 \mathrm{~mm}$ mesh-size net bags (for storage of organisms). To put the assemblages on the pillars in relation to the natural flora and fauna in the bay, scrape-off samples from six randomly chosen areas of vertical rock walls $60 \mathrm{~cm}$ above the seafloor were taken at the fifth sampling occasion (Fig. 1). The samples from six natural vertical rock walls were collected using the same method as for the pillars. The collected benthic fauna and algae were identified to species or nearest 

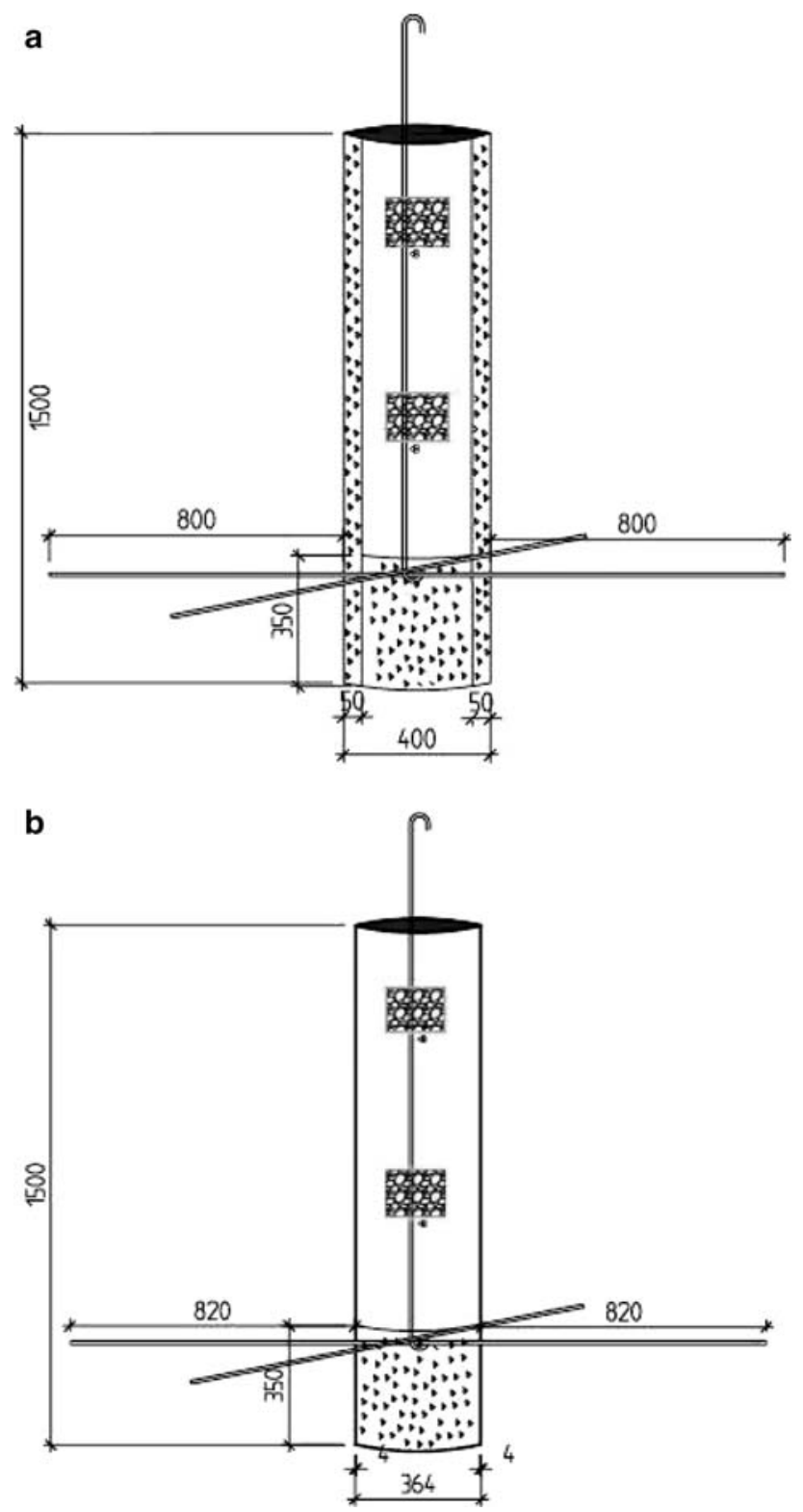

Fig. 2 Drawings of the concrete (a) and steel (b) pillars used in this field experiment. The squares on the pillars are the locations of the photographed surfaces. All measurements are in millimetres

higher taxonomic level and abundance and wet weight was recorded.

A modified point-based visual census procedure was used for fish counts (Sale and Douglas 1981). To minimize observational bias errors, the same investigator counted all fish. The diver slowly moved around the structure; first at a distance of $2 \mathrm{~m}$ noting all visible fish that were present around the structure and then at closer range, recording cryptic species. Two minutes of sampling was carried out at each pillar. Both juveniles and adults of all species were counted during the survey. To avoid mis-identification, Pomatoschistus minutus (sand goby) and Pomatoschistus microps (common goby) were grouped together as Pomatoschistus spp. (Edlund et al. 1980). The fish assemblage on natural soft bottoms and vertical rock walls was sampled using the same technique and investigated water volume as for the pillar sites. Fish was counted at all six occasions at the pillars and soft bottom sites, but the rock walls were only sampled in months 1,5 and 12 (29, 154 and 366 days after submergence, respectively).

Data analysis

Multivariate comparisons of the epibenthic assemblages were performed using the Primer ${ }^{(\mathrm{TM})}$ v6 statistical package. The coverage, abundance and biomass of different species on the two material treatments steel (S) and concrete (C) were compared using Analyses of Similarities (ANOSIM), SIMPER, cluster analysis and multidimensional scaling (MDS) based on rank similarity matrices using Bray-Curtis similarity measures (Clarke 1993). The data was square root or fourth root transformed to decrease the effect of dominant species in the analysis. A one-way ANOSIM was performed for each sampling occasion as each pillar was revisited. Scrape-off samples from the fifth sampling occasion were used to test the effect of direction (south-west and north-east; principal current directions), on species abundance and biomass. In addition, samples from the rock wall (CH) sites were compared with the pillars in terms of species number and abundance, and biomass to compare artificial and natural surfaces. Algae and hydroids were excluded in the abundance analysis due to difficulty separating individuals. Species number was tested using an ANOVA and Tukey HSD as post hoc test.

Due to the difficulty in separating the hydroid Laomedea sp. from algae (mostly filamentous red and brown algae) in the photos, they were grouped together as one group. However, scrape-off samples revealed that algae were rare on the pillars until the fourth sampling occasion. For the same reason, the tunicates Ascidiella scabra and A. aspersa were grouped together as Ascidiella spp. Small areas of rust developed on some of the steel pillar, inhibiting recruitment to some extent. These areas were excluded in the coverage analysis.

To test if the introduced pillars had any influence on the fish assemblage, effects of substrate (concrete, steel, soft bottom and vertical rock walls) and time (1-6) on fish abundance and species number were tested using generalized linear mixed models (GLMMs) with Poisson error distribution and $\log$ link function. Both treatment and time were entered as fixed factors in the model. All pillars and reference sites were revisited during the survey, resulting in repeated measures. Therefore, individual pillars and sites were entered as a random factor and also as subjects within the analysis to prevent pseudo replication. The three fish 


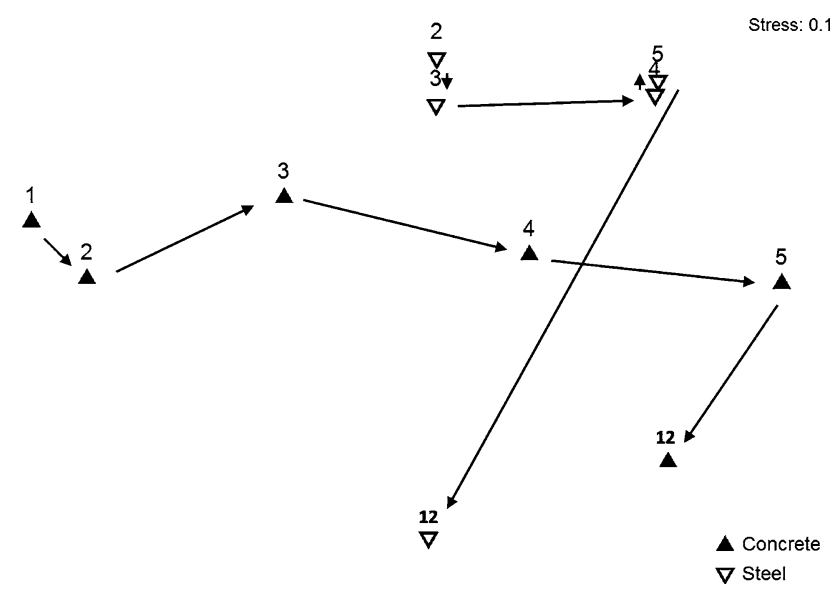

Fig. 3 Multidimensional scaling plot of group average (\%coverage) of epibenthic invertebrates and algae assemblages from steel and concrete pillars at every sampling occasion (month) after deployment $(1=29$ days, $2=64$ days, $3=94$ days, $4=129,5=154,12=366$ days). Steel pillars from the first sampling occasion were outliers as few or no species were recorded on them resulting in low similarity $(<10 \%)$. As a consequence, they were excluded from the plot

species that dominated in abundance (Pomatoschistus spp., Gobiusculus flavescens and Ctenolabrus rupestris) were also tested separately with the same model.

\section{Results}

Epibenthic assemblage

A total of 62 species were identified in the scrape-off samples, divided into ten phyla and 14 families. Out of these, 23 species were exclusively present on the artificial substrates, although none of them were new to the area. The MDS plot (Fig. 3) shows how the group averages of each treatment are distributed in time (months after deployment). Steel pillars from the first sampling occasion were outliers as few or no species were recorded on them, resulting in low similarity $(<10 \%)$. As a consequence they were excluded from the plot. The concrete pillars had a continuous recruitment and succession phase over time (the data points are further away from each other) whilst the steel pillars form two small clusters for the first five sampling occasions. In the follow-up study after 1 year (366 days), the assemblages had changed compared to previous occasions, and by this time the steel pillars were more similar to the concrete pillars than previously sampled steel pillars.

\section{Recruitment and succession on pilings}

There was no effect of height ( 30 or $60 \mathrm{~cm}$ above the seabed) on the epibenthic coverage on each pillar as the oneway permutation test showed low dissimilarities for all sampling occasions for each treatment (ANOSIM, $R<0.250$ ), and the two subsamples were therefore pooled for each pillar. The recruitment and succession patterns in terms of coverage were to some extent similar between concrete and steel pillars (Fig. 4). However, the concrete pillars experienced a more rapid colonization than steel pillars in the first 4 months. After 1 year, both materials show an almost $100 \%$ coverage of organisms on the photographed areas.

The first visible recruits on the pillars were, after 1 month (29 days), the hydroid Laomedea sp., the bay barnacle Balanus improvisus, and the bryozoa Electra sp. The assemblage structure differed significantly between materials (ANOSIM, $R=0.552, P=0.002$ ). The dense coverage of the hydroids on concrete explains this difference (SIMPER, 98\%).

Recruits of several species of solitary ascidians, including Ciona intestinalis, A. scabra, A. aspersa and Corella parallelogramma, and the keel tubeworm, Pomatoceros triqueter, were recorded in the second sampling, 64 days after submergence. A more dissimilar assemblage structure was now noticed compared to the previous month (ANOSIM, $R=0.711, P=0.002$ ) due to the preference of $P$. triqueter and the tunicates for the steel pillars. However, the hydroid was still the species that contributed the most to the dissimilarity (SIMPER, 68\%), followed by P. triqueter (SIMPER, $15 \%$ ) and C. intestinalis (SIMPER, 10\%).

The hydroid domination on concrete had decreased after 3 months (94 days) in favour of the solitary ascidians and to some degree $P$. triqueter. The assemblage structures were significantly different (ANOSIM, $R=0.375, P=0.034$ ). More species contributed to the dissimilarity (SIMPER; Laomedea sp. $41 \%$, the solitary ascidians $43 \%$ and P. triqueter $14 \%$ ).

The coverage of the hydroid had decreased on both materials after 4 months in favour of the ascidians on concrete and $P$. triqueter on steel. The two assemblages were no longer significantly different by this time (ANOSIM, $R=0.254, P=0.052$ ). This was caused by the ascidian $C$. intestinalis (SIMPER, 28\%) that had taken over as the dominant species on both materials, followed by Ascidiella spp. (SIMPER, 21\%). However, the coverage of P. triqueter had increased on steel but not on concrete (SIMPER, $16 \%$ ). Small numbers of filamentous brown and red algae (Sphachelaria sp., Ceratium sp., Aglaothamnion sp., Polysiphonia sp.) entangled among the hydroids were noticed in the scrape-off samples taken.

In the fifth survey in October, 154 days after submergence, $C$. intestinalis showed coverage of nearly $100 \%$ on one of the concrete and two of the steel pillars. This is illustrated by the cluster analysis where these three pillars form a distinct cluster (Fig. 5). The coverage of Ascidiella spp. had increased on concrete but not on steel which resulted in a significantly different assemblage structure (ANOSIM, 
Fig. 4 Overview of recruitment and succession of dominating epibiotic organism on the pillars; a concrete pillar and $\mathbf{b}$ steel pillar. Data are presented as percent coverage per $140 \mathrm{~cm}^{2}$ in months after submergence. Note the compressed interval between month 5 and 12. Species; 1 indicates Laomedea sp. and algae, 2 indicates Pomatoceros triqueter, 3 indicates Ciona intestinalis, 4 indicates Corella parallelogramma, 5 indicates Ascidiella spp., 6 indicates Electra sp. and 7 indicates Balanus improvisus
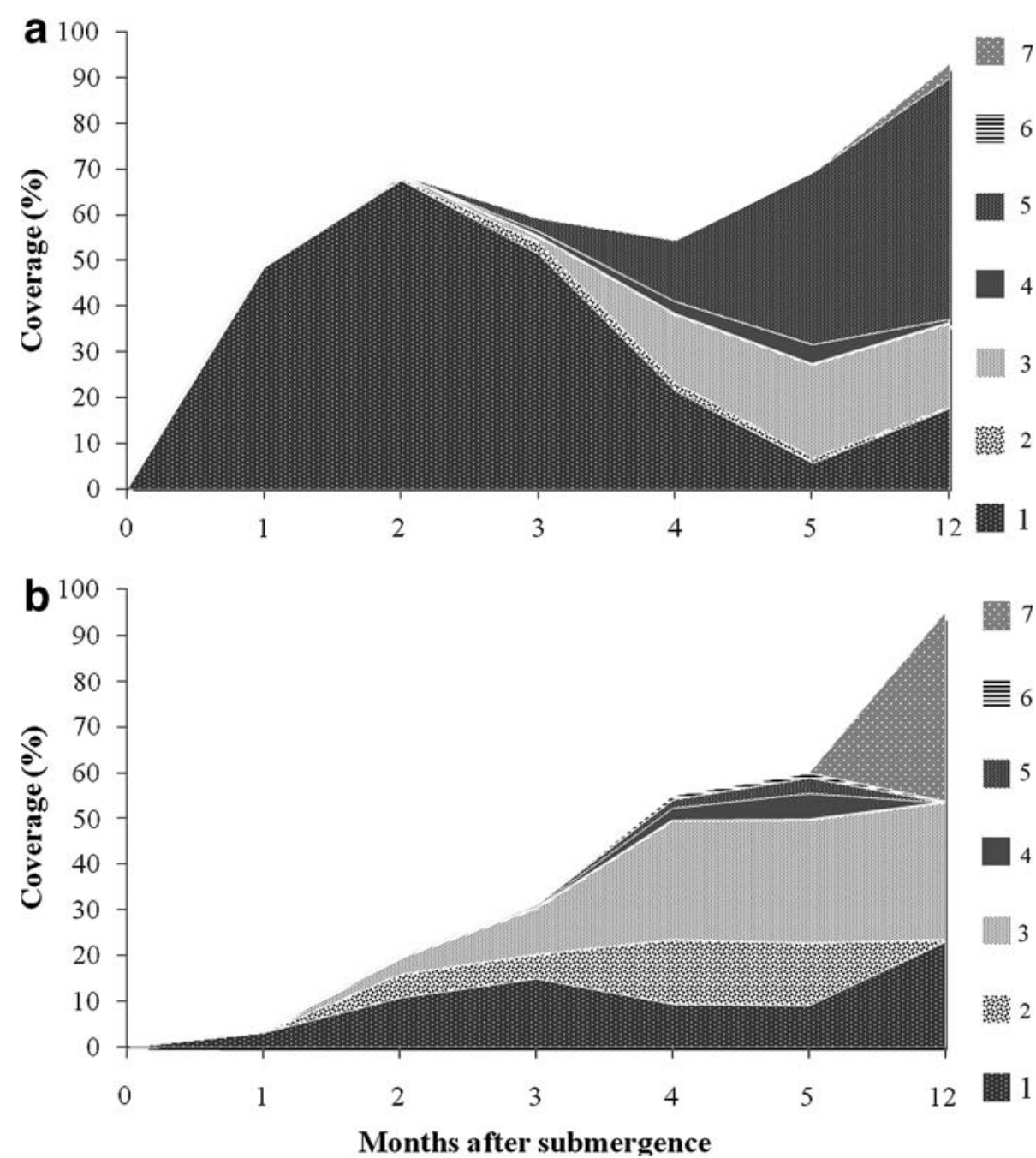

$R=0.354, P=0.006$, SIMPER, 31\%) and the two treatments form distinct clusters in Fig. 5. The similarity of pillar S6s to the concrete pillars is explained by the occurrence of Ascidiella spp. More species of algae were found among the hydroids which could conceal a greater reduction in the coverage of Laomedea sp. (Fig. 4; Electronic supplementary material).

The scrape-off samples from the fifth survey revealed randomly distributed small bivalves, polychaetes, gastropods and juvenile crustaceans $(<1 \mathrm{~cm})$ such as Hyas sp. and Macropodia rostrata as well as several species of amphipods among the hydroids and tunicates (ESM). In addition, several tube worms, $P$. triqueter, were found alive beneath the dense cover of the tunicate. There was no effect of the two different directions (south-west and north-east) on each pillar within each material (ANOSIM, $R<0.100, P>0.05$ ) in terms of biomass and species abundance calculated from the scrap-off samples. Data from the two sides were therefore pooled before differences between the materials were tested. Neither biomass nor species number differed between the steel and concrete pillar (ANOSIM, $R<0.100$, $P>0.01)$. The four species of tunicates constituted $66 \%$ of all individuals recorded (excluding algae and hydroids) and $95 \%$ of the biomass on both steel and concrete. Average species number did not differ significantly between treatments; concrete 9.6, SD 2.9 and steel 8.5, SD 4.5 (ANOVA, $F=2.45, P=0.12$ ) per $100 \mathrm{~cm}^{2}$.

In May 2006, 12 months after submergence, high numbers of new recruits of $B$. improvisus were recorded, primarily on steel pillars. The tube worm, P. triqueter, was almost absent in the photos due to the increased coverage of barnacles. However, since no scrape-off samples were taken at this time, there is no information whether they were alive underneath the barnacles or not. Most ascidians showed similar coverage as during autumn; however, especially $C$. intestinalis were covered with a fine layer of sediment and epiphytic growth on their tunica. The hydroid coverage increased on both treatments, as seen in Fig. 3. However, as it was shown on previous sampling occasions that filamentous brown and red algae were found among the 


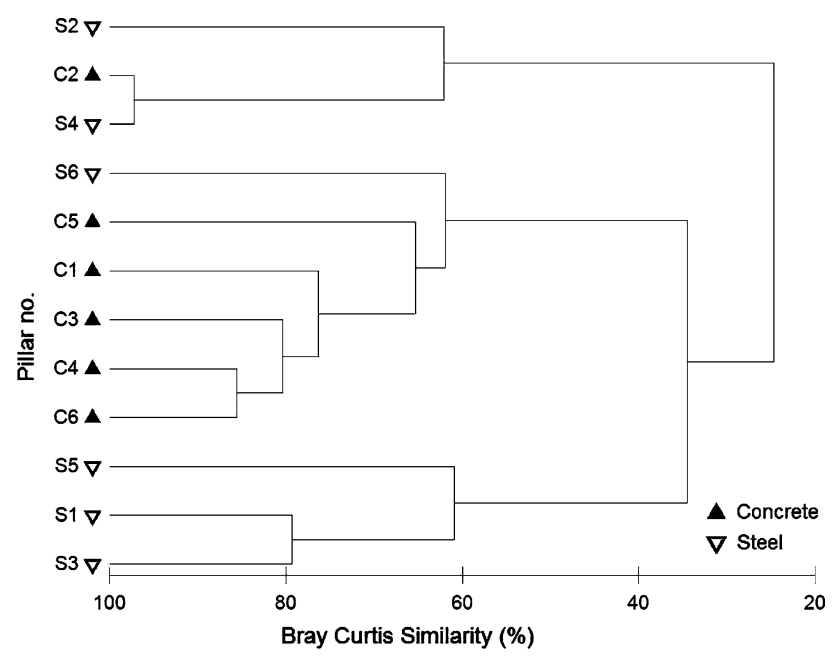

Fig. 5 Dendrogram of the relationship between the individual pillars epibenthic invertebrate and algae assemblage structure after 5 months, 154 days after submergence. Material type and individual pillar number are shown. The cluster containing $S 2, C 2$ and $S 4$ are the pillars dominated by the tunicate Ciona intestinalis

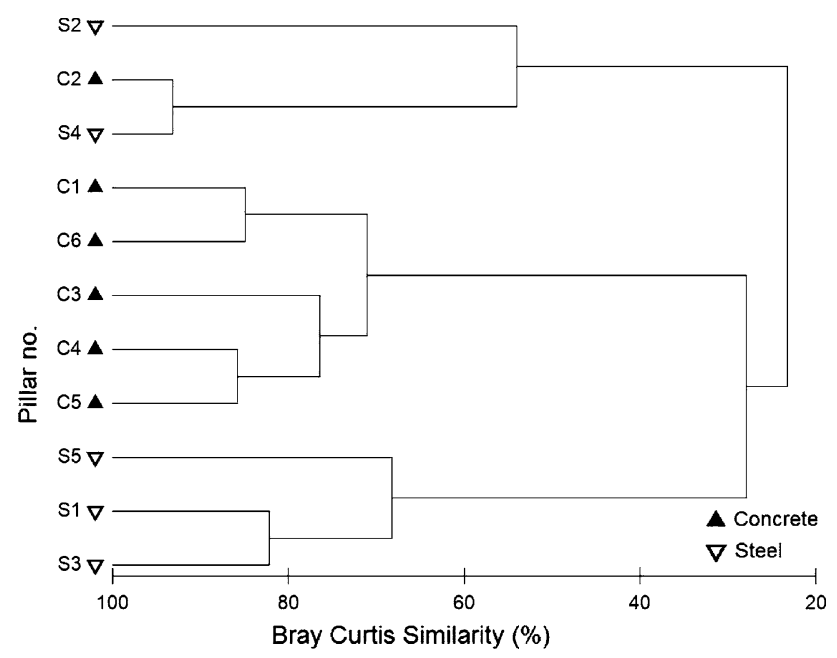

Fig. 6 Dendrogram of the relationship between the individual pillars epibenthic invertebrate and algae assemblage structure after 1 year, 366 days after submergence. Material type and individual pillar number are shown. The cluster containing $S 2, S 4$ and $C 2$ are the pillars dominated by the tunicate Ciona intestinalis. Data from pillar S6 is missing and therefore not included in the cluster analysis

hydroids, the coverage of this group could be somewhat misleading as the algae are expected to increase whit time. The assemblage structure was significantly different between steel and concrete (ANOSIM, $R=0.413$, $P=0.011$ ) with Laomedea sp. (including algae), Ascidiella spp. and B. improvisus as the species contributing to the highest degree to the dissimilarity (SIMPER, 46, 21 and $12 \%$, respectively). The three pillars with $C$. intestinalis once again grouped together in a cluster, Fig. 6.

\section{Natural vertical rock walls}

The vertical rock walls south of the pillars were dominated by the red alga Polysiphonia sp. with turfs of Bonnemaisonia hamifiera attached to the stems. The invertebrate assemblage on the algae consisted of the tunicate A. scabra, the gastropod Bittium reticulatum and several species of amphipods (ESM). The barnacle Balanus balanus was the most abundant barnacle on the vertical rock walls; this can be compared to the pillars where B. improvisus dominated. At the fifth sampling occasion (154 days after submergence) when all pillar were sampled, the average species number was 8.7 (SD 4.5) per $100 \mathrm{~cm}^{2}$, which is not significantly different from the artificial substrates. However, the average biomass and species abundance were higher on steel and concrete and dissimilar compared to the rock walls (ANOSIM; Biomass CH-S, $R=0.368, P=0.009$, CH-C $R=0.819, P=0.002$ and Species abundance: $\mathrm{CH}-\mathrm{S}$, $R=0.448, P=0.002$, CH-C, $R=0.531, P=0.002$ ). The differentiating species on both materials compared to rock walls was $C$. intestinalis, which was almost absent on the rock walls. Another difference was that the dominating alga on the rock walls was the red alga Polysiphonia sp. with corticated basal parts that resulted in high biomass, whilst samples from the pillars were young filamentous plants with low biomass. A. scabra was found on the rock walls and on both types of pillar and was the main contributing species in the species abundance analysis (SIMPER; CH-S $19 \%$ and $\mathrm{CH}-\mathrm{C} 15 \%$ ).

Fish assemblage

A total number of nine fish species, from six families, were recorded with Pomatoschistus spp., Gobiusculus flavescens and Ctenolabrus rupestris being the most common. Overall, average fish densities (Fig. 7) and species number (ESM) were significantly higher at the pillars compared to the soft bottom (GLMM, $P<0.001)$ but not between the material types and the vertical rock walls. The last survey, 1 year (366 days) after submergence, showed an overall low density of fish although Pholis gunnellus (rock gunnel) including both juveniles and adults were observed for the first time on the pillars. The general trend over time for $G$. flavescens and $C$. rupestris was a higher mean abundance at the pillars and hard substrate compared to the soft bottom sites (GLMM, $P<0.0001)$. Time and interaction, treatment $\times$ time, were factors that differed between species. Both $G$. flavescens and $C$. rupestris had three times higher abundances at the pillars compared to the soft bottom habitat 3, 4 and 5 months after submergence. This increase in density was mainly due to new recruits. Pomatoschistus spp. showed the same pattern of increase in the late summer month although they were not influenced 


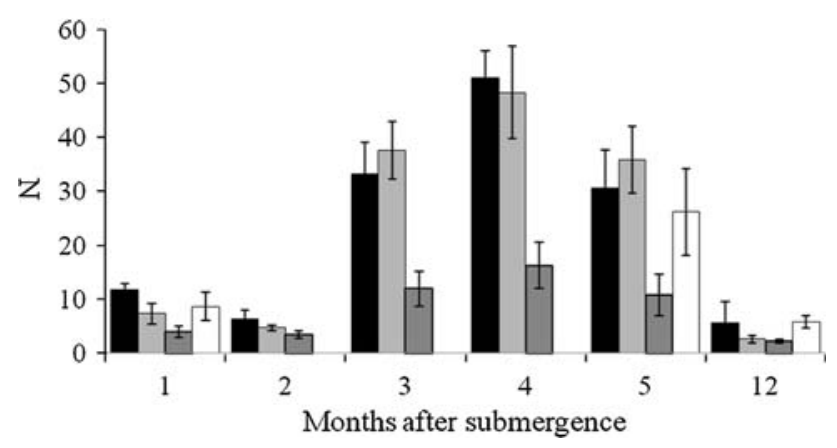

Fig. 7 Abundance (mean \pm SE) of fish per month after submergence around the pillars and natural areas; concrete pillar (black), steel pillar (light grey), control soft bottom (dark grey) and control vertical rock walls (white). Note the compressed interval between months 5 and 12

by the pillars (GLMM, $P=0.104$ ). Patterns in distribution of Gobius niger (black goby) resembled that of G. flavescens and $C$. rupestris although in lower numbers.

\section{Discussion}

Studies have shown that material composition and surface structure play an important role in affecting the character of epibenthic communities on artificial underwater surfaces (Mullineaux and Garland 1993; Anderson and Underwood 1994; Walters and Wethey 1996; Glasby 2000; BecerraMuñoz and Schramm Jr 2007). In this study, we followed the recruitment and succession of epibenthic organisms and fish on vertical cylindrical structures of steel and concrete during 5 months and then returned 1 year after the start of the experiment for a limited sampling. The structures used in the experiment are commonly found in various manmade submerged structures including offshore wind turbine foundations and bridge pillars.

\section{Recruitment and succession of epibenthos on pilings}

The organisms that colonized the two different pillar types were mainly tunicates, hydroids, barnacles, mussels and serpulid worms. The photo-analysis showed that the two materials did initially attract a similar set of species but with different coverage, resulting in a significantly different community structure at five out of six occasions over 1 year. Several small organisms with low abundance were recorded in the scrape-off samples, 5 months after submergence, but not in the photos, resulting in increased differences within each material and a non-significant difference between materials in terms of biomass and species abundance. Nevertheless, the photos register the larger organisms that have been successful in their colonization of the substrate, and it should be noted that a difference could be seen between materials in terms of coverage.
The succession of colonizers found in this survey showed a resemblance to what Hatcher (1998) in the UK and Svensson et al. (2007) at the west coast of Sweden noticed, both having the same submergence time of the year (i.e. starting the experiment in May) as observed in this study. They recorded an initial settlement of barnacles and serpulid worms followed by hydroids and tunicates. As found in this study and others, material characteristics are important regulators influencing the early development of invertebrate assemblages (cf. Anderson 1996; Todd 1998; Berntsson etal. 2000; Stebbing 2002; Chapman and Clynick 2006). In addition, following the initial recruitment, the substratum will change, which could alter subsequent settlement. This may favour certain species as well as hinder others from settling (Sutherland 1978; Osman and Whitlatch 1995; Svensson et al. 2007).

How and why certain species are more successful in settling on artificial substrates has been linked to boundarylayer flows (reviewed in Koehl 2007). Lemire and Bourget (1996) showed in a panel experiment with different heterogeneity at a millimetre scale that barnacles avoided surfaces with $1 \mathrm{~mm}$ grooves and settled more frequently on smooth panels. Barnacles have also been shown to have a competitive advantage on smooth surfaces and their own presence may enhance new settlement of the same species (Chabot and Bourget 1988; Berntsson et al. 2000). These results agree with the present study, where barnacles occurred more frequently on steel than on the more rough concrete surfaces and higher numbers of new recruits were noticed after 1 year on pillars with resident adults. In a study by Mullineaux and Garland (1993), the tube-building polychaete Hydroides diantus showed a moderate avoidance of regions with high turbulence in the boundary layer. Accordingly, the serpulid worm in this study (Pomatoceros triqueter) preferred steel. However, P. triqueter was a poor competitor for space as it was overgrown by ascidians and barnacles (there may have been living serpulid worms underneath the barnacles). Living worms were noticed beneath the dense layer of Ciona intestinalis at the fifth sampling occasion.

The hydroid Laomedea sp. was more inclined to settle on concrete. Hydroids have been observed to prefer a rougher surface that experience high turbulence in the boundary layer (Mullineaux and Garland 1993). Later, the dense cover of hydroids may have enhanced the recruitment of solitary ascidians onto the pillars, including A. aspersa, A. scabra, C. intestinalis and Corella parallelogramma. Schmidt (1983) suggested in his study, in which he used submerged plastic panels, that hydroids (Tubularia larynx) enhance settlement of ascidians by making the substrate more attractive through current reduction and light attenuation. Hence, in the present study, colonies of Laomedea sp. were succeeded 
by large numbers of ascidians. The developed epibenthic community will affect the small-scale hydrodynamic and decrease the effect of the original substrates' roughness (Koehl 2007). Young filamentous red and brown algae appeared after 3-4 months and most likely contributed to the increase of hydroids/algae seen on the pillars after 1 year. The algae did not show any preference for either material.

There were no significant differences on either invertebrate or algae species abundance or biomass between the two sides sampled on each pillar (north-east and south-west as they are the principal current directions in the area) after 5 months. However, the results cannot be correlated to current velocity as this was not measured. There was no difference in coverage of sessile invertebrates between the two photos taken at 30 and $60 \mathrm{~cm}$ above the seafloor. The pillars might have been too small to show any vertical zonation and also the relative shallow depth $(6-8 \mathrm{~m})$ could be a factor (Glasby 1999a).

The colonization of $C$. intestinalis was highly stochastic as it had a nearly $100 \%$ coverage on two steel pillars and one concrete pillar whilst it was almost absent on the others. Eggs and larvae of $C$. intestinalis have been noticed to be maintained in a mucus string that could cause local aggregations (Havenhand and Svane 1991; Petersen and Svane 1995). Further, the species may have a competitive advantage as observed in a study by Svensson et al. (2007) in which it excluded all competitors. When one species becomes as dominant as $C$. intestinalis in this study, species richness is depressed (Blum et al. 2007); ascidians are effective competitors for space and may inhibit other species to settle by predation of settling larvae. The other solitary tunicates noted in this study were not as competitive since when they occurred in dense groups they were significantly smaller than the Ciona assemblage or they occurred only as single individuals.

Sessile filtrating organisms trap nutrients from the water mass and transport them into the seabed in the form of organic debris. This was especially apparent around the pillars covered with $C$. intestinalis as the nearby water around the pillars was filled with small faecal pellets that slowly sank to the sea floor. This input of organic matter to the surrounding sediment may lead to increased biological activity around the base of the pillars. However, Zettler and Pollehne (2006) found in a similar experiment, as in this study, that too much input of organic debris to the sediment may lead to anoxia around the base of an artificial structure. On the other hand, their experiment was performed in stratified water and over a longer period and there was no indication of anoxia around the base of the pillars in the present study. However, it is not impossible that this could occur in the future if there is a long period of poor water circulation.
Natural rock walls compared to the pillars

The vertical rock walls sampled in this study showed similar species numbers after 5 months as the pillars but biomass and species abundance differed. On the rock walls, the red alga Polysiphonia sp. dominated in terms of biomass even though the plants had been heavily grazed and only the corticated stems remained covered with tunicates. Most species found on the natural walls were also represented on the pillars. However, the 23 species only occurring on the pillars were all indigenous to the area. Notably, the vertical rock walls have a different surface roughness, material and history and it is not likely that the same type of assemblages will develop over time on the pillars (see Glasby 1999b; Bulleri et al. 2005; Perkol-Finkel et al. 2006). Further, the individual pillars are smaller in size than the vertical rock walls and both hydrodynamics and light availability are different.

Fish assemblage

Results showed that the pillars influenced the local fish community, as higher densities were recorded near the pillars compared to the surrounding soft bottom habitat. The attraction to the pillars was immediate, as fishes were associated with several pillars within hours of the submersion. There were, however, no difference between the different materials in terms of fish abundance and species number at any occasion. Similar fish numbers and species were noted on the rock walls as in the vicinity of the pillars which could be the result of the two habitats being similar in terms of being dominated by hard substrates, even though the rock wall sites are part of a larger reef and the pillars are a series of single units.

The increase in abundance during sampling occasions 3 and 4 was mainly caused by new recruits of two species. The later decline in fish abundance at the fifth sampling occasion was probably due to a combination of predation and migration. The low water temperature in May $2006\left(<6^{\circ} \mathrm{C}\right)$ when fish abundance was low indicates that fish had not returned from the deeper waters. The large variation in water temperature at the Swedish west coast means that a potential reef effect is likely to be influenced by seasonality. This could explain the significant interaction between time and treatment in this study as the recruitment of juvenile fish in these waters occurs during the summer month and movement by fish to deeper waters takes place during the winter. Seasonal changes in abundance of observed fish species due to migration has been reported from both the North Sea and the Baltic Sea (Thorman 1986; Magill and Sayer 2002; Pihl and Wennhage 2002; Wilhelmsson et al. 2006b).

In the present study, the abundances of Ctenolabrus rupestris (goldsinny wrasse) and Gobiusculus flavescens 
(two-spotted goby) increased around the pillars compared to surrounding area. These species are common in the North Sea and East Atlantic (Muus et al. 1999) and are usually associated with three-dimensional structures and prefer to proliferate near hard substrata in shallow waters (Muus et al. 1999; Gjøsaeter 2002). For these species, the function of the added structure seems to be typical for what artificial reefs commonly are expected to achieve, i.e. habitat enhancement. Large numbers of juvenile G. flavescens have also been noticed to associate with pillar-shaped wind turbine foundations (e.g. Wilhelmsson et al. 2006a, Andersson 2008). In a study by Wilhelmsson et al. (2006a), it was suggested that the mussels covering the surface of the structure offered protection for the juvenile fish. Similarly, in the present study, juvenile $C$. rupestris were noticed to use colonies of sea squirts as a refuge.

Whilst $C$. rupestris and G. flavescens were positively influenced by the presence of the pillars, Pomatoschistus spp. was less affected even though it is widespread in the study area (Edlund et al. 1980; Pihl and Wennhage 2002). It is interesting to notice that there was an increase of Pomatoschistus spp. over time with high densities of new recruits after 4 and 5 months. However, the increase was ubiquitous for all treatments including control sites.

\section{Conclusions}

Surface materials influence the epibenthic assemblage at the early succession stages. The invertebrate and algae assemblage structure in terms of coverage was different on the two materials, steel and concrete. This is most likely linked to surface heterogeneity. High abundance of new recruits of one species with a good competitive strategy can lead to total domination on a surface for a long period, as demonstrated by Ciona intestinalis in this study. Introduced artificial structures could play a significant role in giving space-limited species new settling grounds and increase their relative abundance and hence species numbers in an area. Certain fish species could be attracted to the introduced structures which may lead to an increase in fish densities as a result of new habitat opportunities. Seasonality may also play a role in how fish communities are affected by the introduction of man-made structures, especially in cold-temperate regions.

Acknowledgments The authors wish to thank the staff at Kristineberg Marine Researches Station for all support during the field work, especially Hanna, Elisabeth and Linus. We thank K. Gisslin, B. Borg and M. Gullström for comments on the early versions of the manuscript and $\mathrm{H}$. Løvlie for statistical input. Thank you also S. Nylin, H. Kautsky and the anonymous reviewer for valuable comments of late versions of the draft. The project was funded by Gothenburg
University and EU Sixth Framework programme-the DOWNVInD project through Stockholm University. The study was also supported by Skanska, Bosam, KA Systemteknik, Ventab Styr, Råda Plåt och Svets, Bohusbetong and GRG Bygg.

\section{References}

Anderson MJ (1996) A chemical induced settlement of Sydney Rock Oysters, Saccostera commercialis, in laboratory and in the field. Biol Bull 190:350-358

Anderson MJ, Underwood AJ (1994) Effect of substratum on recruitment and development of an intertidal estuarine fouling assemblage. J Exp Mar Biol Ecol 184(2):217-236

Andersson MH (2008) Man-made structures as habitat for marine faunal assembleges, Lic. Thesis, Department of Zoology, Stockholm University, ISNN 1403-5227, 2008:14, pp 75

Andersson MH, Gullström M, Asplund ME, Öhman MC (2007) Importance of using multiple sampling methodologies for estimating fish community composition in offshore wind power construction areas of the Baltic Sea. Ambio 36(8):634-636

Bacchiocchi F, Airoldi L (2003) Distribution and dynamics of epibiota on hard structures for coastal protection. Estuar Coast Shelf Sci 56:1157-1166

Badalamenti F, Chemello R, D'Anna G, Henriquez Ramos P, Riggio S (2002) Are artificial reefs comparable to neighbouring natural rocky areas? A mollusc case study in the Gulf of Castellammare (NW Sicily). ICES J Mar Sci 59:S127-S131

Baine M (2001) Artificial reefs: a review of their design, application, management and performance. Ocean Coast Manage 44(34):241-259

Becerra-Muñoz S, Schramm HL Jr (2007) On the influence of substrate morphology and surface area on phytofauna. Hydrobiologia 575:117-128

Berntsson KM, Jonsson PR, Lejhall M, Gatenholm P (2000) Analysis of behavioural rejection of micro-textured surfaces and implications for recruitment by the barnacle Balanus improvisus. J Exp Mar Biol Ecol 251:59-83

Blum JC, Chang AL, Liljesthröm M, Schenk ME, Steinberg MK, Ruiz GM (2007) The non-native solitary ascidian Ciona intestinalis (L.) depress species richness. J Exp Mar Biol Ecol 342:5-14

Bohnsack JA (1989) Are high densities of fishes at artificial reefs the result of habitat limitation or behavioural preference? Bull Mar Sci 44:631-645

Brown CJ (2005) Epifaunal colonization of the Loch Linnhe artificial reef: influence of substratum on epifaunal assemblage structure. Biofouling 21:73-85

Bulleri F, Chapman MG, Underwood AJ (2005) Intertidal assemblage on seawalls and vertical rocky shores in Sydney Harbour, Australia. Austral Ecol 30:655-667

Chabot R, Bourget E (1988) Influence o substratum heterogeneity and settled barnacle density on settlement of cypris larvae. Mar Biol 97:45-56

Chapman MG, Clynick BG (2006) Experiments testing the use of waste materials in estuaries as habitat for subtidal organism. J Exp Mar Biol Ecol 338:164-178

Clarke KR (1993) Nonparametric multivariate analyses of changes in community structure. Austral Ecol 18:117-143

Clynick BG, Chapman MG, Underwood AJ (2007) Effects of epibiota on assemblages of fish associated with urban structures. Mar Ecol Prog Ser 332:201-210

Connell SD (2001) Urban structures as marine habitats: an experimental comparison of the composition and abundance of subtidal epibiota among pilings, pontoons and rocky reefs. Mar Environ Res $52: 115-125$ 
Connell JH, Slatyer RO (1977) Mechanisms of succession in natural communities and their role in community stability and organization. Am Nat 111(982):1119-1144

Edlund A-M, Sundmark G, Thorman S (1980) The identification of Pomatoschistus pictus, P. microps and P. minutus (Gobiidae, Pisces). Sarsia 65:239-242

Eggleston DB, Elis WE, Etherington LL, Dahlgren CP, Posey MH (1999) Organism responses to habitat fragmentation and diversity: habitat colonization by estuarine macrofauna. J Exp Mar Biol Ecol 236:107-132

Foster MS (1975) Regulation of algal community development in Macrocystis pyrifera forest. Mar Biol 32:331-342

Gill AB, Kimber JA (2005) The potential for cooperative management of elasmobranches and offshore renewable energy development in UK waters. J Mar Biol Assoc UK 85:1075-1081

Girard CG, Benhamou S, Dagorn L (2004) FAD: fish aggregating device or fish attracting device? A new analysis of yellowfin tuna movements around floating objects. Anim Behav 67:319-326

Gjøsaeter J (2002) Distribution and density of goldsinny wrasse (Ctenolabrus rupestris) (Labridae) in the Risor and Arendal along the Norwegian coast. Sarsia 87:75-81

Glasby TM (1999a) Interactive effects of shading and proximity to the seafloor on the development of subtidal epibiotic assemblagaes. Mar Ecol Prog Ser 190:113-124

Glasby TM (1999b) Differences between subtidal epibiota on pier pilings and rocky reefs at Marinas in Sydney, Australia. Estuar Coast Shelf Sci 48:281-290

Glasby TM (2000) Surface composition and orientation interact to affect subtidal epibiota. J Exp Mar Biol Ecol 248:177-190

Guichard F, Bourget E, Robert J-L (2001) Scaling the influence of topographic heterogeneity on intertidal benthic communities: alternate trajectories mediated by hydrodynamics and shading. Mar Ecol Prog Ser 217:27-41

Guilbeau BP, Harry FP, Gambrell RP, Knopf FC, Dooley KM (2003) Algae attachment on carbonated cements in fresh and brackish waters-preliminary results. Ecol Eng 20:309-319

Hatcher AM (1998) Epibenthic colonisation patterns on slabs of stabilized coal-waste in Pools Bay, UK. Hydrobiologia 367:153-162

Havenhand JN, Svane I (1991) Roles of hydrodynamics and larval behaviour in determining spatial aggregation in the tunicate Ciona intestinalis. Mar Ecol Prog Ser 68:271-276

IEA (International Energy Agency) (2008) Wind energy annual report 2007. IEA, Paris, pp 286, ISBN 0-9786383-2-8

Jensen AC, Collins KJ, Lockwood APM (2000) Artificial reefs in European seas. Kluwer Academic Publishers, Dordrecht, p 508

Keough MJ (1984) Effects of patch size on the abundance of sessile marine invertebrates. Ecology 65(2):423-437

Koehl MAR (2007) Mini review: hydrodynamics of larval settlement into fouling communities. Biofouling 23(5):357-368

Lemire M, Bourget E (1996) Substratum heterogeneity and complexity influence micro-habitat selection of Balanus sp. and Tubularia crocea larvae. Mar Ecol Prog Ser 135:77-87

Magill SH, Sayer DJ (2002) Seasonal and interannual variation in fish assemblage of northern temperate rocky subtidal habitats. J Fish Biol 61:1198-1216

Malm T (2005) Biovind; Kraftverkskonstruktioner i havet-en metod för att lokalt öka den biologiska mångfalden i Östersjön. Rapport, Botanical Institution, Stockholm University, pp 14 (In Swedish)

Moreau S, Péroni C, Pitt KA, Connolly RM, Lee SY, Meziane T (2008) Opportunistic predation by small fish on epibiota of jetty pilings in urban waterways. J Fish Biol 72:205-217

Mullineaux LS, Butman CA (1991) Initial contact, exploration, and attachment of barnacle (Balanus amphitrite) cyprids settling in flow. Mar Biol 110:93-103

Mullineaux LS, Garland ED (1993) Larval recruitment in response to manipulative field flows. Mar Biol 116:667-683
Muus BJ, Nielsen JG, Svedberg U (1999) Havsfisk och fiske i Nordvästeuropa. Prisma, Stockholm, p 337 (In Swedish)

Nelson PA (2003) Marine fish assemblages associated with fish aggregating devices (FADs): effects of fish removal, FAD size, fouling communities, and prior recruits. Fish Bull 101:835-850

Osman RW, Whitlatch RB (1995) The influence of resident adults on recruitment: a comparison to settlement. J Exp Mar Biol Ecol 190:169-198

Perkol-Finkel S, Shashar N, Benayahu Y (2006) Can artificial reefs mimic natural reef communities? The role of structural features and age. Mar Environ Res 61:121-135

Petersen JK, Svane I (1995) Larval dispersal in the ascidian Ciona intestinalis (L.). Evidence for closed population. J Exp Mar Biol Ecol 186:89-102

Petersen JK, Malm T (2006) Offshore windmill farms: threats to or possibilities for the marine environment. Ambio 35(2):75-80

Pickering H, Whitmarsh D (1997) Artificial reefs and fisheries exploitation: a review of the 'attraction versus production' debate, the influence of design and its significance for policy. Fish Res 31:39-59

Pihl L, Wennhage H (2002) Structure and diversity of fish assemblage on rocky and soft bottom shores on the Swedish west coast. J Fish Biol 61(Suppl A):148-166

Polovina JJ (1989) Artificial reefs: nothing more than benthic fish aggregators. CalCOFI Rep 30:37-39

Qvarfordt S, Kautsky H, Malm T (2006) Development of fouling communities on vertical structures in the Baltic Sea. Estuar Coast Shelf Sci 67:618-628

Reed DC, Schroeter SC, Huang D, Anderson TW, Ambrose RF (2006) Quantitative assessment of different artificial reef designs in mitigating losses to kelp forest fishes. Bull Mar Sci 78:133-150

Rilov G, Benayahu Y (1998) Vertical artificial structures as an alternative habitat for coral reef fishes in disturbed environments. Mar Environ Res 45(4/5):431-451

Sale PF, Douglas WA (1981) Precision and accuracy of visual census technique for fish assemblage on coral patch reefs. Environ Biol Fish 6(3/4):333-339

Sayer MDJ, Magill SH, Pitcherm TJ, Morissette L, Ainsworth C (2005) Simulation-based investigation of fishery changes as affected by the scale and design of artificial habitats. J Fish Biol 67(Suppl B):218-243

Schmidt GH (1983) The hydroid Tubularia larynx causing 'bloom' of the ascidians Ciona intestinalis and Ascidiella aspersa. Mar Ecol Prog Ser 12:103-105

SMHI (2006) Weather data. SMHIs database SHARK (Svenskt HavsARKiv). Swedish Marine Monitoring program, The Swedish Meteorological and Hydrological Institute, Norrköping

Sousa WP (1984) Intertidal mosaics: patch size, propagule availability, and spatially variable patterns of succession. Ecology 65(6): 1918-1935

Stebbing ARD (2002) Tolerance and hormesis-increased resistance to copper in hydroids linked to hormesis. Mar Environ Res 54:805-809

Sutherland JP (1978) Functional roles of Schizoporella and Stylea in the fouling community at Beaufort, North Carolina. Ecology 59(2):257-264

Svane I, Petersen JK (2001) On the problems of epibioses, fouling and artificial reefs, a review. Mar Ecol 22:169-188

Svensson JR, Lindegarth M, Siccha M, Lentz M, Molis M, Wahl M, Pavia H (2007) Maximum species richness at intermediate frequencies of disturbance: consistency among level of productivity. Ecology 88(4):830-838

Thorman S (1986) Seasonal colonisation and effects of salinity and temperature on species richness and abundance of fish in some brackish and estuarine shallow waters in Sweden. Holarct Ecol 9(2):126-132 
Todd CD (1998) Larval supply and recruitment of benthic invertebrates: do larvae always disperse as much as we believe? Hydrobiologia 375/376:1-21

Wahl M (1989) Marine epibiosis. I. Fouling and antifouling: some basic aspects. Mar Ecol Prog Ser 58:175-189

Walters LJ, Wethey DS (1996) Settlement and early postsettlement survival of sessile marine invertebrates on topographically complex surfaces: the importance of refuge dimensions and adult morphology. Mar Ecol Prog Ser 137:161-171

Wilhelmsson D, Öhman MC, Ståhl H, Shlesinger Y (1998) Artificial reefs and dive tourism in Eilat, Israel. Ambio 27:764-766
Wilhelmsson D, Malm T, Öhman MC (2006a) Influence of offshore wind power on demersal fish. ICES J Mar Sci 63:775-784

Wilhelmsson D, Yahya SAS, Öhman MC (2006b) Effects of high structures on cold temperate fish assemblage: a field experiment. Mar Biol Res 2:136-147

Zettler ML, Pollehne F (2006) The impact of wind engine constructions on benthic growth pattern in the western Baltic. In: Köller J, Köppler J, Peters W (eds) Offshore wind energy, research on environmental impacts. Springer, New York, pp 201-222. ISBN 3540346767 